\title{
Glycaemic control and its associated factors in type 2 diabetic patients in Amman, Jordan
}

\author{
M. Adham, ${ }^{7}$ E. Sivarajan Froelicher, ${ }^{1,2}$ A. Batieha ${ }^{3}$ and K. Ajlouni ${ }^{7}$
}

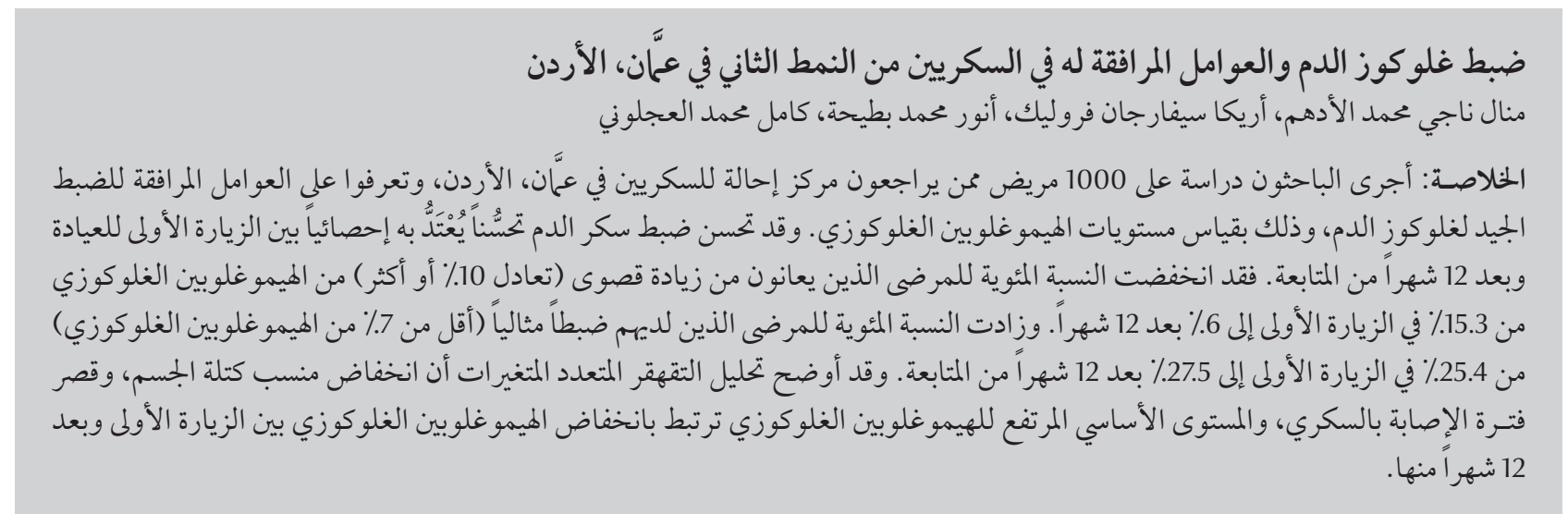

ABSTRACT A study of 1000 patients attending a diabetes referral centre in Amman, Jordan, identified factors associated with good glycaemic control, as measured by glycosylated haemoglobin (HbA1c) levels. Glycaemic control improved significantly between the first clinic visit and at 12-months follow-up. The proportion of patients with extreme $\mathrm{HbA1c}(\geq 10 \%)$ decreased from $15.3 \%$ to $6.0 \%$ after 12 months. The percentage of patients with optimal control $(\mathrm{HbA1c}<7 \%$ ) increased from $25.4 \%$ at the first visit to $27.5 \%$ at 12 -month follow-up. Multivariate regression showed that low body mass index, shorter duration of diabetes and higher baseline HbAlc were related to reductions in $\mathrm{HbA1c}$ between the first and 12-month visits.

Contrôle de la glycémie et facteurs associés chez des patients souffrant de diabète de type 2 à Amman (Jordanie)

RÉSUMÉ Une étude sur 1000 patients consultant dans un centre d'orientation-recours spécialisé dans le traitement du diabète à Amman (Jordanie) a mis en évidence les facteurs associés à un bon contrôle de la glycémie, mesuré par les taux d’hémoglobine glycosylée (HbA1c). Le contrôle de la glycémie s'est amélioré de manière significative entre la première visite au centre et le suivi réalisé 12 mois plus tard. La proportion de patients présentant un taux de HbAlc extrêmement élevé ( $\geq 10 \%$ ) est passée de $15,3 \%$ à 6,0 \% à l'issue des 12 mois. Le pourcentage de patients présentant un contrôle optimal (HbA1c $<7 \%$ ) est passé de 25,4 \% lors de la première visite à 27,5\% lors de la consultation de suivi effectuée 12 mois plus tard. La régression multivariée a mis en évidence qu'un faible indice de masse corporelle, un diabète de plus courte durée et une ligne de base du taux de HbA1c plus élevée étaient associés à une baisse du taux de HbAlc entre la première consultation et celle réalisée 12 mois après.

'National Centre for Diabetes, Endocrinology and Genetics, University ofJordan, Amman, Jordan (Correspondence to K. Ajlouni: ajlouni@ju.edu.jo). ${ }^{2}$ Univeristy of California San Francisco, San Francisco, California, United States of America.

3 Jordan University of Science and Technology, Irbid, Jordan.

Received: 01/07/08; accepted: 29/09/08 


\section{Introduction}

The increasing prevalence of type 2 diabetes mellitus (DM) worldwide is reaching epidemic proportions and is becoming a major public health problem [1]. DM is a chronic disease that needs coordinated efforts between the patient, family and medical team. Improving glycaemic control is a high priority in decreasing the burden of DM and delaying its complications [2,3]. While research has identified patient characteristics that influence glycaemic control in type $1 \mathrm{DM}$, little is known about the factors that influence glucose control in type $2 \mathrm{DM}[4]$; such information has the potential to reduce the short- and long-term complications associated with DM.

A patient's glycosylated haemoglobin (HbAlc) level is an indicator of the status of glycaemic control over the previous 3 months. A cut-off point of < $7 \%$ indicates optimal glycaemic control, but may not be feasible to achieve for all diabetics [5]. Nevertheless, the UK Prospective Diabetes Study found that in type 2 diabetics each percentage point reduction in $\mathrm{HbAlc}$ was associated with a $35 \%$ reduction in microvascular complications and a $7 \%$ reduction in all-cause mortality [6].

The objectives of this study were to investigate the extent of glycaemic control, as measured by $\mathrm{HbAlc}$, in patients with type $2 \mathrm{DM}$ attending the National Centre for Diabetes, Endocrinology and Genetics in Amman (NCDEG), Jordan; to assess the relationship between various demographic and clinical factors and glycaemic control; and to assess the factors related to changes in HbAlc at 12-month follow-up.

\section{Methods}

This was a historical prospective study design using a review of patients' medical records from an existing database, supplemented by a structured interview questionnaire designed for this study.

\section{Setting}

NCDEG was established in 1996 as a part of the University of Jordan hospital in Amman, Jordan. The centre provides comprehensive diabetes care to patients from all over the country by a team consisting of an endocrinologist, specialized nurses, physicians and a dietician. An established database of medical records contains each patient's clinical history. In addition, there are several specialized clinics related to complications of DM.

\section{Sample}

All patients with type $2 \mathrm{DM}$ who had made 2 or more visits to the centre 2 to 3 months apart between July and December 2006, and for whom followup data were available over a 12-month period, were eligible for the study.

The required sample size was estimated assuming that the proportion of diabetics with poor glycaemic control was $50 \%$, the level of significance $(\alpha)$ equal to 0.05 and limits of error $5 \%$. The estimated sample size calculated for the given prevalence at $95 \%$ confidence interval (CI) was 778 . We deliberately over-sampled $(n=1000)$ in order to account for missing data from medical records.

Approval for the study was obtained through the ethical committee of the centre. Verbal consent was obtained from each subject for access to the medical records and the interview.

\section{Measurement and data collection}

The interview was administered by a registered nurse and included information on sociodemographic variables (education, monthly family income and marital status) and also asked about smoking and patients' use of medication. Educational status was classified by the length of time in education: 0 years (illiterate), $1-12$ years (school) or $\geq 12$ years of education (diploma, bachelors and postgraduate education). Smoking was categorized as nonsmoker (never smoked) or smoker (regularly smoked at least 1 cigarette daily).

Data obtained from the patients' records included: treatment for diabetes, measurements of blood pressure (BP), anthropometric measurements for body mass index (BMI), fasting blood sugar, $\mathrm{HbAlc}$, lipid profile, kidney function tests and eye and foot examinations obtained at each visit.

Anthropometric measurements included weight (in light clothes to the nearest $0.5 \mathrm{~kg}$ ), height (without shoes to the nearest $0.5 \mathrm{~cm}$ ) and waist circumference (at the narrowest point between the umbilicus and the rib cage) and hip circumference (at the widest part of the body below the waist). BMI (weight in kilograms/height in metres squared) was used to classify patients as normal weight $\left(<25 \mathrm{~kg} / \mathrm{m}^{2}\right)$, overweight $\left(25-29.9 \mathrm{~kg} / \mathrm{m}^{2}\right)$ or obese $(\mathrm{BMI}>30$ $\left.\mathrm{kg} / \mathrm{m}^{2}\right)$.

Blood pressure was measured using a standard sphygmomanometer (EN 1060, Riester). Hypertension was defined as systolic $\mathrm{BP} \geq 130 \mathrm{mmHg} /$ or diastolic $\mathrm{BP} \geq 80 \mathrm{mmHg}$ or regular use of antihypertensive drugs).

Complications of DM such as retinopathy, neuropathy and nephropathy were noted from the records. Ophthalmic examination was done at each visit by dilating the pupil of one eye with mydriatic eye drops. Retinopathy was classified as present or absent.

\section{Laboratory measures and biochemical analysis}

The primary outcome measure was HbAlc (at baseline and 12 months). $\mathrm{HbAlc}$ represents an estimate of mean glucose level over the last 120 days [7]. Current guidelines for glycaemic control recommend $\mathrm{HbAlc}$ values $<7 \%$ as a treatment goal for most DM patients [8]. HbAlc was analysed by using a high-performance liquid chromatography method (Bio-Rad). Glycaemic control was grouped into 4 categories: 
good $(\mathrm{HBA1C}<7 \%)$, acceptable ( $\mathrm{HbAlc} 7 \%-7.9 \%)$, poor ( $\mathrm{HbAlc}>$ $8 \%-9.9 \%)$ or extremely inadequate $(\mathrm{HbAlc} \geq 10 \%)$.

Total cholesterol, triglycerides (TG) and high-density lipoprotein (HDL) and low-density lipoprotein (LDL) cholesterol were analysed by an enzymatic colorimetric method (Cobas Integra). Lipid profile cut-offs were: high total cholesterol $(\geq 200 \mathrm{mg} / \mathrm{dL})$; high serum $\mathrm{TG}(\geq 150 \mathrm{mg} / \mathrm{dL})$; low HDL cholesterol $(<45 \mathrm{mg} / \mathrm{dL})$; AND high LDL cholesterol $(\geq 100 \mathrm{mg} / \mathrm{dL})$.

Albumin urea concentrations were measured by urine dipstick (Klinitic).

\section{Statistical analysis}

Data were entered and analysed using SPSS software. Data was screened for extreme outliers, logical inconsistencies and errors. Means and standard deviation (SD) and frequencies described the sample. Student paired $t$-test was used to assess the difference in means between the first clinic visit and 12-month follow-up intervals. The chi-squared test was used to assess statistical significance for differences of categorical variables; $P \leq 0.05$ was considered statistically significant. Multivariate linear regression was used to assess the independent effect of variables related to change in $\mathrm{HbAlc}$ level between the first and follow-up visits after controlling for potential confounders.

\section{Results}

\section{Sociodemographic and clinical characteristics at the first visit}

Table 1 shows the sociodemographic characteristics of the sample of 1000 patients with type $2 \mathrm{DM}$ at baseline. The mean age was 58.1 (SD 9.3) years, with $48.3 \%$ of patients aged $>60$ years; $50.5 \%$ of patients were female, $10 \%$ were illiterate and $15 \%$ were current smokers. The mean duration of DM was 9.4 (SD 7.2) years. One-third of patients had

\begin{tabular}{|c|c|c|}
\hline Variable & No. of patients & $\%$ \\
\hline \multicolumn{3}{|l|}{ Sex } \\
\hline Male & 495 & 49.5 \\
\hline Female & 505 & 50.5 \\
\hline \multicolumn{3}{|l|}{ Age (years) } \\
\hline$<40$ & 30 & 3.0 \\
\hline $40-49$ & 150 & 15.0 \\
\hline $50-59$ & 337 & 33.7 \\
\hline$\geq 60$ & 483 & 48.3 \\
\hline \multicolumn{3}{|c|}{ Education (years) ${ }^{a}$} \\
\hline 0 & 86 & 10.0 \\
\hline $1-12$ & 392 & 44.6 \\
\hline$>12$ & 398 & 55.4 \\
\hline Current smoker & 145 & 15.0 \\
\hline
\end{tabular}

${ }^{a}$ Data on education missing for 124 patients.

retinopathy and two-thirds had dyslipidaemias (Table 2). More than half of the patients were on oral hypoglycaemic drugs and only $2.1 \%$ were managed by diet alone. Obesity $\left(\mathrm{BMI}>30 \mathrm{~kg} / \mathrm{m}^{2}\right)$ was present in $57.6 \%$ of patients and $91.3 \%$ were overweight or obese.

The overall mean $\mathrm{HbAl}$ c level at the first visit to the clinic was $8.10 \%$; only $24.1 \%$ of patients had $\mathrm{HbAl} c<7 \%$ (Table 2), while $16.1 \%$ had extremely high values ( $\geq 10 \%)$. The lipid profile at the first visit to the clinic showed that $22.8 \%$ had high total cholesterol, $43.6 \%$ high TG, 57.4\% low HDL cholesterol and 62.8\% high LDL cholesterol. Microalbuminurea was present in $32.0 \%$ and a large proportion (71.7\%) were hypertensive $(\mathrm{BP} \geq 130 / 80 \mathrm{mmHg})$.

Sex differences in selected sociodemographic and clinical characteristics are shown in Table 3. Males were significantly older and had a longer duration of diabetes, longer duration of education, lower HDL cholesterol and LDL cholesterol levels and lower mean $\mathrm{HbAlc}$ at the first visit.

\section{Glycaemic control at the first visit}

Mean $\mathrm{HbAlc}$ levels by patient's age, sex and clinical characteristic at the first visit are shown on Table 4. Males had significantly lower mean $\mathrm{HbAlc}$ levels than females $(P=0.02)$. HbAlc levels increased with a longer duration of DM $(P=0.001)$. Age was not related to glycaemic control. Patients with BMI $25-29 \mathrm{~kg} / \mathrm{m}^{2}$ had the lowest mean $\mathrm{HbAlc}$ levels and $\mathrm{HbAlc}$ was significantly different comparing patients with $\mathrm{BMI}<25$ and $\geq 30 \mathrm{~kg} /$ $\mathrm{m}^{2}$. Hypercholesterolaemia, elevated LDL cholesterol and the presence of microalbuminurea were found in those with higher $\mathrm{HbAlc}$ levels (all $P$-values $<0.01$ ). A higher HbAlc level was significantly associated with the presence of retinopathy $(P<0.001)$. Patients treated with insulin, or a combination of insulin and hypoglycaemic agents, had significantly higher $\mathrm{HbAlc}$ levels.

\section{Changes in glycaemic control at 12-month follow-up}

Mean $\mathrm{HbAlc}$ decreased significantly in the subset of patients who had measurements at follow-up, from $8.1 \%$ (SD 1.8\%, range $4.7 \%-17.3 \%$ ) at the first visit to $7.8 \%$ (SD 1.3\%, range $4.9 \%-13.6 \%$ ) at follow-up.

The distribution of $\mathrm{HbAlc}$ levels for 886 patients for whom complete data were available at the first and 12-month follow up visits are shown on Table 5. 


\begin{tabular}{|c|c|c|c|}
\hline \multicolumn{4}{|c|}{$\begin{array}{l}\text { Table } 2 \text { Clinical and laboratory characteristics of diabetic patients at the first clini } \\
\text { visit }(n=\mathbf{1 0 0 0})\end{array}$} \\
\hline Variable & No. of patients & $\%$ & Mean value (SD) \\
\hline Duration of diabetes (years) & & & $9.4(7.2)$ \\
\hline$<5$ & 303 & 30.3 & \\
\hline $5-9$ & 279 & 27.9 & \\
\hline $10-19$ & 284 & 28.4 & \\
\hline$\geq 20$ & 134 & 13.4 & \\
\hline HbA1c level (\%) & & & $8.10(1.80)$ \\
\hline$<7$ & 241 & 24.1 & \\
\hline $7-7.9$ & 301 & 30.1 & \\
\hline $8-9.9$ & 296 & 29.6 & \\
\hline$\geq 10$ & 161 & 16.1 & \\
\hline Total cholesterol (mg/dL) & & & $173.7(38.2)$ \\
\hline$<200$ & 672 & 77.2 & \\
\hline$\geq 200$ & 198 & 22.8 & \\
\hline Triglycerides (mg/dL) & & & $158.3(84.5)$ \\
\hline$<150$ & 492 & 56.4 & \\
\hline$\geq 150$ & 381 & 43.6 & \\
\hline HDL cholesterol (mg/dL) & & & $44.3(11.1)$ \\
\hline$\geq 45$ & 360 & 42.6 & \\
\hline$<45$ & 486 & 57.4 & \\
\hline LDL cholesterol $(\mathrm{mg} / \mathrm{dL})$ & & & $113.1(32.1)$ \\
\hline$<100$ & 321 & 37.2 & \\
\hline$\geq 100$ & 542 & 62.8 & \\
\hline Urine albumin present & 314 & 32.0 & \\
\hline Retinopathy present & 326 & 33.4 & \\
\hline Dyslipidaemia present & 671 & 68.0 & \\
\hline Hypertension present ${ }^{a}$ & 717 & 71.7 & \\
\hline$B M I\left(k g / m^{2}\right)$ & & & $31.6(5.4)$ \\
\hline$<25$ & 86 & 8.7 & \\
\hline $25-29.9$ & 335 & 33.7 & \\
\hline $30-34$ & 329 & 33.1 & \\
\hline$\geq 35$ & 244 & 24.5 & \\
\hline \multicolumn{4}{|l|}{ Type of treatment } \\
\hline Oral hypoglycaemics & 524 & 52.9 & \\
\hline Insulin \& oral hypoglycaemics & 368 & 37.8 & \\
\hline Insulin & 77 & 7.8 & \\
\hline Diet alone & 21 & 2.1 & \\
\hline
\end{tabular}

${ }^{a}$ Systolic $B P>130 \mathrm{mmHg}$, diastolic $B P>80 \mathrm{mmHg}$.

$S D=$ standard deviation; $H b A 7_{C}=$ glycosylated haemoglobin; $H D L=$ high-density lipoprotein, $L D L=$ lowdensity lipoprotein; $B M I=$ body mass index.

The percentage of patients with optimal control $(\mathrm{HbAlc}<7 \%)$ increased from $25.4 \%$ at the first visit to $27.5 \%$ at follow-up. The proportion with extreme $\mathrm{HbAlc}$ levels ( $\geq 10 \%$ ) decreased from $15.3 \%$ to $6.0 \%$ between the first and 12-month visit $(P<0.001)$. and neuropathy were found not to be confounders) (Table 6). Patients with initially high $\mathrm{HbAlc}$ level were more likely to decrease their $\mathrm{HbAl}$ c level. The regression coefficient $(\beta=0.7)$ showed that for each $1 \%$ higher initial $\mathrm{HbAlc}$, there was a $0.7 \%$ greater reduction in the $\mathrm{HbAlc}$ at the last visit $(P<0.001)$. The longer the duration of DM the less likely it was that a patient would have a reduced $\mathrm{HbAlc}$ between the 2 visits $(\beta=-0.16, P<0.001)$. Similarly, the higher the BMI the lower the reduction in $\mathrm{HbAlc}$ between the 2 visits $(\beta=-0.09, P<0.001)$.

\section{Discussion}

This is the only study from Jordan to report on glycaemic control in a large sample of patients that included subjects who attended this referral centre from all parts of Jordan. NCDEG delivers fully integrated specialized health care for patients with DM, endocrine and genetic diseases, serving both the private and public sector in Amman and elsewhere in the country. The rate of optimal glycaemic control ( $\mathrm{HbAlc}$ $<7 \%)$ among the study sample $(27.5 \%$ at 12 months) was comparable to that reported from many countries [9-11]. Extremely inadequate control ( $\mathrm{HbAlc}$ $\geq 10 \%$ ) was rare among the study group (6.0\% at 12 months). An HbAlc level of $<7 \%$ as a proposed target for optimum glycaemic control in DM patients may not be feasible or practical and has been the subject of considerable discussion [11-13]. The results of our study are consistent with those by Benoit et al. [2] and Abdelazis et al. [12].

Factors related to better glycaemic control included male sex, shorter duration of DM and lower levels of total cholesterol, LDL cholesterol and TG. A meta-analysis found that only about one-third of patients were controlled to an $\mathrm{HbAlc}$ level of $<7 \%$ [12]. Achieving or maintaining levels of $<7 \%$ is more difficult in patients with a longer duration 


\begin{tabular}{|c|c|c|c|c|c|}
\hline \multirow[t]{2}{*}{ Variable } & \multicolumn{2}{|c|}{ Males } & \multicolumn{2}{|c|}{ Females } & \multirow[t]{2}{*}{$P$-value } \\
\hline & No. of patients & Mean value (SD) & No. of patients & Mean value (SD) & \\
\hline Age (years) & 494 & $58.8(9.9)$ & 506 & $57.3(9.3)$ & 0.01 \\
\hline Education (years) & 405 & $13.7(4.6)$ & 402 & $8.7(5.4)$ & $<0.001$ \\
\hline Duration of diabetes (years) & 493 & $9.9(7.4)$ & 505 & $8.8(7.0)$ & 0.02 \\
\hline $\operatorname{HbAlc}(\%)$ & 491 & $8.07(1.77)$ & 505 & $8.30(1.83)$ & 0.04 \\
\hline LDL cholesterol level (mg/dL) & 434 & $107.6(30.6)$ & 441 & $118.1(33.2)$ & $<0.001$ \\
\hline HDL cholesterol level (mg/dL) & 432 & $41.2(10.0)$ & 440 & $48.4(19.1)$ & $<0.001$ \\
\hline Systolic BP (mmHg) & 490 & $129.6(21.1)$ & 506 & $131.1(60.7)$ & 0.62 \\
\hline Diastolic BP (mmHg) & 490 & $78.0(11.1)$ & 505 & $78.0(10.7)$ & 0.94 \\
\hline BMI $\left(\mathrm{kg} / \mathrm{m}^{2}\right)$ & 493 & $31.5(5.3)$ & 502 & $31.7(5.4)$ & 0.46 \\
\hline
\end{tabular}

$S D=$ standard deviation $; H B A 7 C=$ glycosylated haemoglobin $\angle D L=$ low-density lipoprotein; $H D L=$ high-density lipoprotein; $B P=$ blood pressure $; B M I=$ body mass index.

ofDM. Rather than targeting an $\mathrm{HbAlc}$ level of $<7 \%$ for all diabetic patients, individualization of the target levels has been suggested [13]. However, while the risk of complications declines as $\mathrm{HbAlc}$ declines, the risk of hypoglycaemia increases. The balance between benefit and harm of intensive treatment may be less favourable in children $<13$ years or adults over 70 years, and in people with repeated severe hypoglycaemia, or those who lack awareness of hypoglycaemia [14]. In patients with advanced DM complications, such as blindness, end-stage renal disease, advanced autonomic neuropathy or cardiovascular disease, the benefit of more intensive treatment may be limited by comorbidity and reduced life expectancy. In such patients, less stringent goals for glycaemic control may be adopted [14]. A number of studies have demonstrated that immediate feedback to the patient about their $\mathrm{HbAlc}$, intense education and ensuring appropriate changes in therapy results in a significant shortterm and long-term improvement of glycaemic status and enhances DM care [15-17]. This will help in individualizing target $\mathrm{HbAlc}$ levels according to patient's preference, age, social, psychological status and other risk factors.

Optimal glycaemic control was recorded in $24.1 \%$ of our patients at their initial visit, a figure which increased modestly to $27.5 \%$ at the last follow-up visit. Such a level of control is consistent with the results of many studies. In Saudi Arabia, for example, only $27 \%$ of the study group reached the target level of control, and the author explained this as due to poor eating habits, poor compliance with medication and the use of inappropriate herbal medicines [9]. In Kuwait, only $17.6 \%$ of patients had achieved the goal of HbAlc $<7 \%$ [10]. In Finland, only 25\% of a study group had HbAlc $<7.3 \%$ [11]. However, optimal control was reported in $44 \%, 50 \%$ and $58 \%$ of patients from NHANES III [18], the UK Prospective Diabetes Study [6] and a study in the Netherlands [19]. The decline in HbAlc levels in our study between the first and 1-year follow-up visits suggests that patients may not have been receiving optimum management before visiting NCDEG, leaving room for further improvement in control of their DM. It is possible that physicians who treat patients in the community have more relaxed standards of control that permit higher levels of glycaemia. Lack of resources, including lack of facilities for $\mathrm{HbAlc}$ measurement, unavailability of medications and lack of educational efforts regarding diet and weight are alternative explanations.

Glycaemic control in our study was related to a number of factors including sex, duration of DM, BMI, dyslipidaemia and treatment modality. Consistent with our findings, women were found to have worse glycaemic control than men in Saudi Arabia; the author related this to the social norms of women in some conservative Arab communities which limit their ability to take up exercise or employment outside the home [9]. Similar findings were reported from Finland [11]. However, a study from the United States found that adult men with insulin-dependent type $2 \mathrm{DM}$ had significantly poorer glycaemic control than did women [4].

Our data showed that longer duration of DMwas related to more difficulty with maintenance of glycaemic control. This finding is consistent with 3 earlier studies $[6,11,20]$ but is contradicted by another report [4]. The worsening of glycaemic control over time could be explained by a reduction in pancreatic beta cell function and an increased fat mass, particularly visceral adiposity, leading to greater insulin resistance associated with the ageing process. It is known that achieving and maintaining $\mathrm{HbAl}$ c levels $<7 \%$ is difficult in patients with a longer duration of DM even with the addition of a third oral hypoglycaemic drug. Hypoglycaemia remains a major limiting factor in achieving tight glycaemic control with insulin.

In our study, $91.3 \%$ of patients were overweight or obese. BMI appears to be related to glycaemic control. The lack of a relationship between age and 


\begin{tabular}{|c|c|c|c|}
\hline Variable & No. of patients ${ }^{a}$ & Mean HbA1c level\% (SD) & $P$-value \\
\hline Total & 1000 & $8.10(1.80)$ & \\
\hline \multicolumn{4}{|l|}{ Sex } \\
\hline Male & 496 & $8.05(1.76)$ & \multirow{2}{*}{0.02} \\
\hline Female & 504 & $8.31(1.82)$ & \\
\hline \multicolumn{4}{|l|}{ Age (years) } \\
\hline$<40$ & 30 & $8.40(2.58)$ & \multirow{4}{*}{0.29} \\
\hline $40-49$ & 150 & $8.10(1.81)$ & \\
\hline $50-59$ & 337 & $8.30(1.80)$ & \\
\hline$\geq 60$ & 82 & $8.10(1.73)$ & \\
\hline \multicolumn{4}{|l|}{ Duration of diabetes (years) } \\
\hline$<5$ & 303 & $7.74(1.91)$ & \multirow{4}{*}{$<0.001$} \\
\hline $5-9$ & 278 & $8.20(1.68)$ & \\
\hline $10-19$ & 284 & $8.48(1.72)$ & \\
\hline$\geq 20$ & 134 & $8.50(1.74)$ & \\
\hline \multicolumn{4}{|l|}{ Total cholesterol (mg/dL) } \\
\hline$<200$ & 671 & $7.97(1.64)$ & \multirow{2}{*}{$<0.001$} \\
\hline$\geq 200$ & 198 & $8.78(2.06)$ & \\
\hline \multicolumn{4}{|l|}{ HDL cholesterol (mg/dL) } \\
\hline$>45$ & 360 & $8.13(1.74)$ & \multirow{2}{*}{0.95} \\
\hline$\leq 45$ & 485 & $8.14(1.79)$ & \\
\hline \multicolumn{4}{|l|}{ LDL cholesterol (mg/dL) } \\
\hline$<100$ & 321 & $7.93(1.63)$ & \multirow{2}{*}{0.05} \\
\hline$\geq 100$ & 541 & $8.28(1.85)$ & \\
\hline \multicolumn{4}{|l|}{ Triglycerides (mg/dL) } \\
\hline$<150$ & 492 & 7.99 (1.71) & \multirow{2}{*}{0.02} \\
\hline$\geq 150$ & 380 & $8.36(1.85)$ & \\
\hline \multicolumn{4}{|l|}{ Retinopathy } \\
\hline Retinopathy & 326 & $8.58(1.79)$ & \multirow{2}{*}{$<0.001$} \\
\hline No retinopathy & 649 & $7.96(1.76)$ & \\
\hline \multicolumn{4}{|l|}{ Proteinurea } \\
\hline Proteinurea & 307 & $8.50(1.90)$ & \multirow{2}{*}{$<0.001$} \\
\hline No proteinurea & 628 & $8.03(1.73)$ & \\
\hline \multicolumn{4}{|l|}{ Type of treatment } \\
\hline Oral hypoglycaemics & 524 & $7.87(1.64)$ & \multirow{4}{*}{$<0.001$} \\
\hline Insulin & 77 & $8.47(1.99)$ & \\
\hline Insulin \& oral hypoglycaemics & 367 & $8.58(1.86)$ & \\
\hline Diet & 21 & $7.27(1.78)$ & \\
\hline \multicolumn{4}{|l|}{ Blood pressure $(\mathrm{mmHg})$} \\
\hline$<130 / 80$ & 238 & $8.10(1.94)$ & \\
\hline$\geq 130 / 80$ & 716 & $8.21(1.73)$ & 0.4 \\
\hline \multicolumn{4}{|l|}{$B M I\left(k g / m^{2}\right)$} \\
\hline$<25$ & 86 & $8.25(2.23)$ & \multirow[t]{4}{*}{0.01} \\
\hline $25-29$ & 335 & $7.91(1.70)$ & \\
\hline $30-34$ & 328 & $8.37(1.71)$ & \\
\hline$\geq 35$ & 244 & $8.27(1.82)$ & \\
\hline
\end{tabular}

${ }^{a}$ Not all proportions add up to 1000 due to some missing values.

$S D=$ standard deviation; $H D L=$ high-density lipoprotein; $L D L=$ low-density lipoprotein; $B M I=$ body mass index. 


\begin{tabular}{|c|c|c|c|c|c|}
\hline \multirow[t]{2}{*}{ HbAlc (\%) } & \multicolumn{2}{|c|}{ Baseline } & \multicolumn{2}{|c|}{ 12-month follow-up } & \multirow[t]{2}{*}{$P$-value } \\
\hline & No. of patients & $\%$ & No. of patients & $\%$ & \\
\hline$<7$ & 225 & 25.4 & 244 & 27.5 & \multirow{4}{*}{$<0.001$} \\
\hline $7-7.9$ & 266 & 30.0 & 302 & 34.1 & \\
\hline $8-9.9$ & 260 & 29.3 & 287 & 32.4 & \\
\hline$\geq 10$ & 135 & 15.2 & 53 & 6.0 & \\
\hline
\end{tabular}

glycaemic control in our study is inconsistent with the findings of a number of studies $[2,19]$ which reported that younger age was associated with poorer glycaemic control [19]. As in other studies, patients treated with insulin, or a combination of insulin and hypoglycaemic agents, were found to have poorer glycaemic control $[2,19,21]$. This may be related to the fact that patients treated by insulin or combination therapy have more severe disease that requires more aggressive treatment to control their disease, while patients with milder disease are more easily controlled by diet or oral hypoglycaemic agents.

Our study also concurs with others that showed a significant positive relationship between $\mathrm{HbAlc}$ and elevated total and LDL cholesterol [2,19,22]. In our sample, $75.8 \%$ of patients had uncontrolled DM, as indicated by $\mathrm{HbAlc} \geq 7 \%$. Although high TG and low HDL represent the typical pattern of diabetic dyslipidaemia, such a pattern was not evident in our study, probably because the patients had been treated with lipid-lowering drugs. Because of the multiplicative cardiovascular risk of hyperglycaemia and dyslipidaemia, lipid abnormalities should be treated aggressively as part of a comprehensive DM care programme.

\begin{tabular}{|c|c|c|}
\hline Variable & $\beta$ regression coefficient & $P$-value \\
\hline HbA1c level & 0.70 & $<0.001$ \\
\hline Duration of diabetes & -0.16 & $<0.001$ \\
\hline BMI & -0.09 & $<0.001$ \\
\hline
\end{tabular}

$B M I=$ body mass index .
Factors related to greater improvement in HbAlc levels at follow-up in our study included higher initial HbAlc, shorter duration of DM and lower BMI. To our knowledge, this is the first study in Jordan to report on changes in $\mathrm{HbAlc}$ level during a follow-up period.

\section{Limitations}

Several limitations affect the generalizability of our study findings to all diabetic patients in Jordan. This study used convenience sampling and, although patients receiving care in NCDEG patients may differ from diabetics in the general population in certain aspects such as socioeconomic status, severity of their disease and health awareness and motivation. It is reasonable to assume that the rate of optimal control in patients treated outside the centre is lower.

Patients with only 1 prior visit to the clinic were excluded and therefore patients who lived outside Amman may have been less likely to meet the inclusion criteria of having attended NCDEG more than twice, creating a selection bias between residents of Amman and those outside of Amman. Thus, patients with poor metabolic control or came from all over Jordan, the sample of

less interest in their disease may have been excluded.

The use of secondary data is associated with inherent limitations because study variables that are desirable to know may not be contained in the data. Detailed data about some aspects of patient management at baseline were not available in this study. Such data, such as changes in drug management, could account the improvements in HbAlc levels. Such details would be useful to assess in future studies.

Certain important aspects were not available to the us in this study, such as physical activity levels and compliance of patients with the treatment protocol; both are likely to influence glycaemic control. To clarify these limitations a prospective longitudinal study is needed that includes all patients attending NCDEG, information about distance of travel to the centre and other variables, a longer follow-up period than the current 12 months and more comprehensive information on all relevant variables.

Nevertheless, this study had multiple strengths. The study objectives were achieved at in a short time at relatively low cost and. Important research questions were answered using the rich and complete data source of the medical records of NCDEG.

\section{Conclusions}

The proportion of optimal glycaemic control among the study population at 12 -month follow up (27.7\%) was comparable to that reported from many countries. Extremely inadequate control (HbAlc $\geq 10 \%)$ was rare among the sample. Factors related to better glycaemic control at 12 months after the first clinic visit included male sex, shorter duration of diabetes and lower levels of total cholesterol, LDL cholesterol and TG. Multivariate linear regression analysis showed that factors related to greater changes in $\mathrm{HbA} 1 \mathrm{clevel}$ included higher initial $\mathrm{HbAlc}$, shorter duration of DM and lower BMI. 


\section{References}

1. King H, Aubert R, Herman W. Global burden of diabetes, 1995-2025: prevalence, numerical estimates, and projections Diabetes Care, 1998, 21:1414-1431.

2. Benoit S, Fleming R, Philis-Tsimikas A. Predictors of glycemic control among patients with type 2 diabetes: longitudinal study. BMC Public Health, 2005, 5(1):36 (doi: 10.1186/1471-2458 -5-36).

3. Sidorove J et al. Disease management for diabetes mellitus: impact of HbA1c. American Journal of Managed Care, 2000, 6:1217-1226.

4. Nichols $\mathrm{G}$ et al. Predictors of glycemic control in insulin-using adult with type 2 diabetes. Diabetes Care, 2000, 23:273-277.

5. Gavin LA et al. Troglitazone add-on therapy to a combination of sulfonylureas plus metformin achieved and sustained effective diabetes control. Endocrine practice, 2000, 6:305-310.

6. UK Prospective Diabetes Study (UKPDS) Group. Intensive blood-glucose control with sulphonylureas or insulin compared with conventional treatment and risk of complications in patients with type 2 diabetes (UKPDS 33). Lancet, 1998, 352:837-853.

7. Goldstein DE et al. Tests of glycemia in diabetes. Diabetes Care, 2005, 27:87-99.

8. Aisha A, Alghamdi. Role of HbA1c in the management of diabetes mellitus. Saudi Medical Journal, 2004, 3:342-345.

9. Akbar DH. Low rates of diabetic patients reaching good control target. Eastern Mediterranean Health Journal, 2001, 7:671-678.

10. Al-Sultan F, Al-Zanki N. Clinical epidemiology of type 2 diabetes mellitus in Kuwait. Kuwait Medical Journal, 2005, 37:98-104.

11. Valle T et al. Glycemic control in patients with diabetes in Finland. Diabetes Care, 1999, 22:575-579.

12. Abdelazis B et al. Facteurs determinants du controle glycemique des patients diabetiques de type 2 suivis en premiere ligne
[Predictive factors of glycemic control in patients with type 2 diabetes mellitus in primary care]. Revue d'Épidemiologie et de Santé Publique, 2006, 54(5):443-52.

13. American Diabetes Association. Standards of medical care for patients with diabetes mellitus. Diabetes Care, 2003, 26(Suppl. 1):33-50.

14. Diabetes Control and Complications Trial Research Group. The absence of a glycemic threshold for the development of long term complications: the perspective of the Diabetes Control and Complications Trial. Diabetes, 1996, 45:1289-1298.

15. Petersen J et al. Effect of point-of-care on maintenance of glycemic control as measured by HbA1c. Diabetes Care, 2007, 30:713-715

16. Cagliero E, Levina E, Nathan D. Immediate feedback of HbA1c levels improves glycemic control in type 1 and insulin-treated type 2 diabetic patients. Diabetes Care, 1999, 22:1785-1789.

17. Thaler $\mathrm{L}$ et al. Diabetes in urban African-Americans. XV11. Availability of rapid HbAlc measurements enhances clinical decision-making. Diabetes care, 1999, 22:1415-21.

18. Saadine J et al. Improvement in diabetes processes of care and intermediate outcomes: United States, 1988-2002. Annals of Internal Medicine, 2006, 144:7465-7474.

19. Goudswaard A et al. Patient characteristics do not predict poor glycemic control in type 2 diabetes patients treated in primary care. European Journal of Epidemiology, 2004, 19:541-545.

20. El-Kebbi I et al. Association of younger age with poor glycemic control and obesity in urban African Americans with type 2 diabetes. Archives of Internal Medicine, 2003, 163:69-75.

21. Spann SJ et al. Management of type 2 diabetes in the primary care setting: a practice-based research network study. Annals of Family Medicine, 2006, 4:23-31.

22. Habib SS, Aslam M. Risk factors, knowledge and health status in diabetic patients. Saudi Medical Journal, 2003, 24:1219-1224. 